\title{
PAISAJES DE LA CRISIS: PROBLEMAS Y OPORTUNIDADES
}

\author{
Emilia Román (Dr. Arquitecta - Profesora asociada DUyOT)
}

\section{PAISAJES DE LA BURBUJA INMOBILIARIA}

En los últimos lustros el paisaje de nuestro país ha sido invadido por numerosas urbanizaciones deshabitadas, con edificios terminados o a medio construir, solares en el interior de las ciudades, terrenos urbanizados vacíos, infraestructuras y equipamientos sin uso, operaciones ruinosas consecuencia de la burbuja inmobiliaria y la crisis económico-financiera.

Estas urbanizaciones y edificios fantasma están presentes en gran diversidad de paisajes de la Península, sobre todo en áreas del litoral pero también en el interior, ubicadas generalmente en terrenos próximos a pueblos y ciudades de nuestra geografía, e incluso en parques y parajes naturales que gozaban de protecciones de escala nacional e internacional.

Un ejemplo de esta última circunstancia es lo ocurrido en el Embalse de Valdecañas (Cáceres) donde, a pesar de ser un humedal de gran importancia a nivel internacional por sus valores naturales ${ }^{70}$, se aprobó con el apoyo del Gobierno de Extremadura la construcción de un resort con dos hoteles y 200 viviendas de lujo, club social, campo de golf y puerto deportivo. Todo bajo su declaración en el año 2007 como Proyecto de Interés Regional (PIR) ${ }^{71}$, es decir, por su utilidad pública, incidencia socio-económica e interés social...

Actualmente el proyecto se encuentra ejecutado al $60 \%$ debido a la crisis económica, pero también a una Sentencia del Tribunal Supremo del año 2014, que confirmaba la ya emitida por el Tribunal Superior de Justicia de Extremadura en 2011, en la que declaraba nulo el PIR. En la sentencia el Tribunal Supremo recuerda la importancia de la legislación sectorial (en este caso ambiental) como condicionante de la ordenación territorial y urbanística: "cuando unos terrenos están sujetos a algún régimen especial de protección sectorial, lo mismo que cuando concurren en ellos valores de los que la legislación urbanística considera merecedores de protección, resulta preceptiva su exclusión del desarrollo urbano y su clasificación como suelo no urbanizable de especial protección" y ordena el derribo del complejo turístico y la reposición y restitución de los terrenos a su estado anterior.

Sin embargo, la Junta de Extremadura se resiste a ejecutar la sentencia asegurando que demoler lo construido conllevaría un gasto de más de 34 millones de euros, a los que habría que añadir los gastos correspondientes a la indemnización del promotor. Además, alega que es menos perjudicial para el medio ambiente dejarlo como está que retornarlo a su situación inicial (se talaron 7.000 eucaliptos y se han plantado unos 8.000 árboles y 100.000 matorrales autóctonos). A día de hoy el resort

\footnotetext{
70 Estaba clasificado como suelo no urbanizable especialmente protegido y pertenecen a la red ecológica europea Red Natura 2000.

71 Información obtenida de Ecologistas en Acción : http://www.ecologistasenaccion.es/article27375.html [Fecha de consulta: 21 de julio de 2015]
} 
continua activo... Ante esta disyuntiva surge una primera cuestión ¿demoler o aprovechar lo construido? ¿Qué es más beneficioso y tiene menos costes para el medio ambiente y para la sociedad?
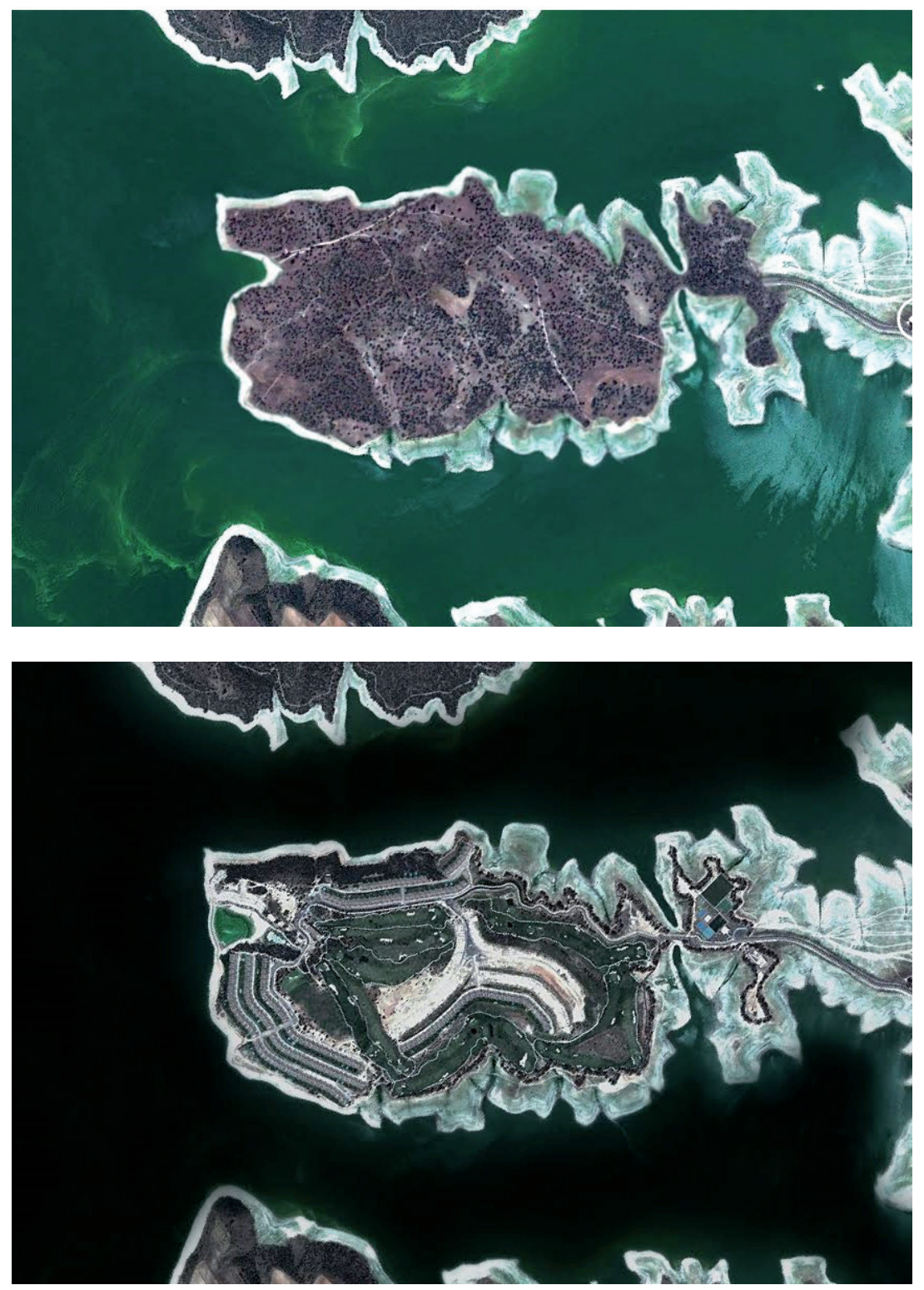

Figura 8. Evolución de Isla de Valdecañas a Campo de Golf Valdecañas , 2002-2013 Fuente: Nación Rotonda

A los problemas ambientales y paisajísticos generados por estas actuaciones se añaden otros de índole socioeconómica, como las familias que, en su día y animadas por el boom inmobiliario, invirtieron sus ahorros en estas viviendas y que actualmente se enfrentan a grandes dificultades no sólo para habitarlas sino también para venderlas o alquilarlas. 
Otros propietarios conviven diariamente con cientos de edificios e infraestructuras abandonadas, espacios libres sin mantenimiento, sin vida social y sin una solución a corto plazo.

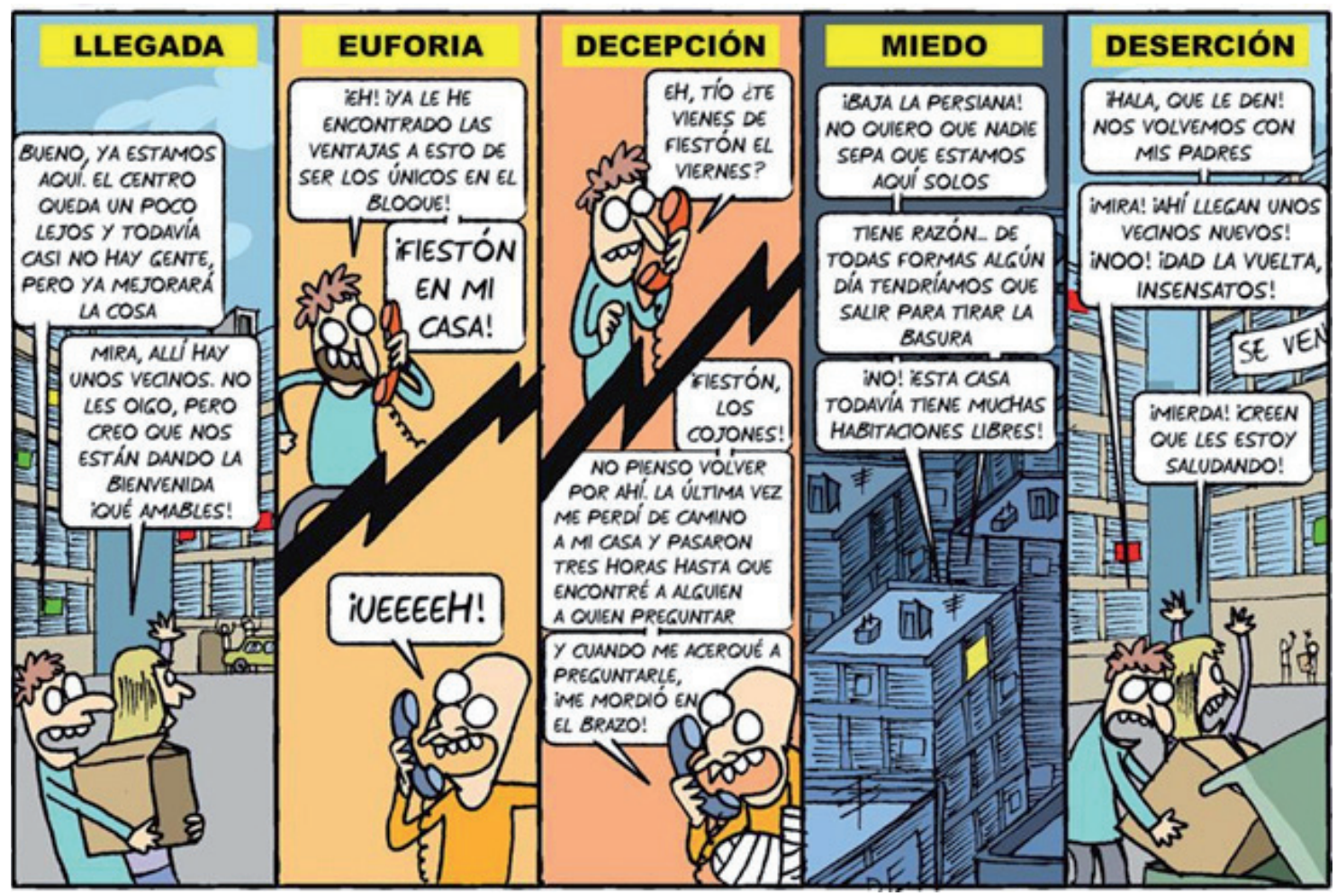

Figura 9. ¿Cómo es la vida en una urbanización fantasma?

Fuente: revista $\mathrm{El}$ jueves ${ }^{72}$

También existen casos de "okupación" por familias con escasos recursos o que han sido desahuciadas y que han encontrado una alternativa en estos lugares, que carecen de los servicios básicos para alcanzar una calidad de vida digna. A este estado de precariedad vital se suma el deterioro y desmantelamiento que han sufrido gran parte de estas zonas debido al paso del tiempo, pero también a hurtos y actos vandálicos. Estos "cadáveres inmobiliarios"73 representan la peor cara de nuestra sociedad, cuyo principal modelo de desarrollo se ha basado en la consideración de la vivienda como un producto, objeto de negocio, y no como un derecho fundamental para los ciudadanos. Se da la paradoja de que en nuestro país existen casi 3,5 millones de viviendas vacías ${ }^{74}$, mientras diariamente escuchamos las dificultades de acceso de la población más joven o historias de familias que no tienen dónde ir. Además España es un país con una de las tasas de natalidad más bajas del mundo: en el año 2014 alcanzó la cifra de 9,14\%o, con un Índice de fecundidad de 1,3275

\footnotetext{
72 http://www.eljueves.es/2013/11/01/como vida una urbanizacion fantasma.html

73 Término utilizado por proyecto colectivo "Cadáveres Inmobiliarios": http://cadaveresinmobiliarios.org/

74 Cifra que no contempla datos de edificios y urbanizaciones a medio terminar.

75 Datos obtenidos de Expansión: http://www.datosmacro.com/demografia/natalidad/espana [Fecha de consulta: 17 de julio de 2015]
} 


\section{ALTERNATIVAS Y OPORTUNIDADES}

Ante este desolador panorama surgen cuestiones relacionadas con nuestras competencias profesionales como ¿Qué hacer con estos nuevos paisajes? ¿Presentan entre sí las mismas características? ¿Cómo afrontar su intervención?. Para resolver estas cuestiones es esencial conocer el número y variedad de casos que existe y, por ello, es preciso su identificación y caracterización. En función de las particularidades de cada ámbito, su localización, estado de desarrollo y de conservación, uso previsto, ocupación, régimen de propiedad, etc. los objetivos de actuación e intervención variarán notablemente. A continuación se exponen algunas alternativas para afrontar este vasto problema.

\section{Inventariado y caracterización}

Leyenda: 6000km (Basurama) Especulación (Ecologistas en Acción) Me-

\section{dit Urban Nación Rotonda Neoruinas (Tenerife) Ruinas modernas}

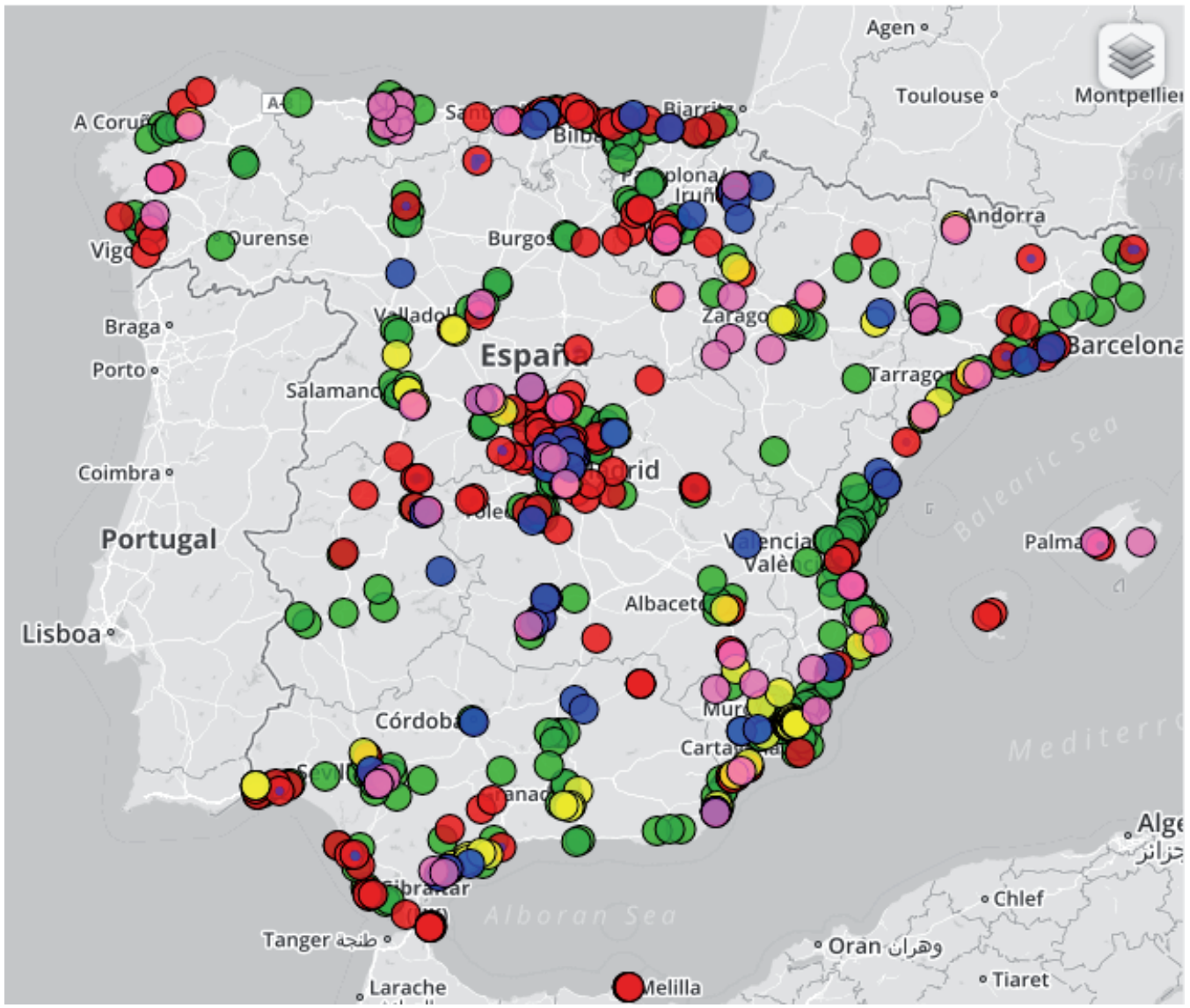

Figura 10. Base de datos post-burbuja

Fuente: Cadáveres Inmobiliarios http://cadaveresinmobiliarios.org/ 
Existen iniciativas cuyo objetivo es comprender y cartografiar la dimensión de la burbuja inmobiliaria española como, por ejemplo, la elaboración de un inventario denominado "Cadáveres Inmobiliarios: Base de datos post-burbuja". Mediante este Sistema de Información Geográfica se ofrecen datos sobre los numerosos casos existentes distribuidos por toda la geografía española. Esta base de datos es completada y mantenida por diversas asociaciones, grupos de investigación y colectivos como Basurama, Ecologistas en Acción, Nación Rotonda, el Grupo de Investigación Medit_Urban, Neoruinas, etc. y también está abierta a la colaboración del público interesado.

\section{Demolición y reposición}

Otra alternativa son las políticas que algunos países aplican a sus ciudades en contracción o menguantes ("Shrinking cities"). Por ejemplo, los planes de demolición de la administración estadounidense para combatir extensas áreas en declive y abandono del noreste del país. La gran diferencia con los crecimientos urbanos de nuestro país es que se abandonaron lugares que nunca fueron habitados, ni siquiera concluidos. Por ello "deberíamos intentar incluir en los planes de nuestras ciudades y en los proyectos de urbanización, la forma de deshacer lo que se propone construir y sus costes ecológicos, ambientales y sociales"76. Existen actuaciones de ámbito local como la de Ses Covetes, al sur de Mallorca, en la que, por resolución del Tribunal Supremo de Justicia de Baleares, el ayuntamiento demolió una urbanización ilegal y actualmente se está finalizando la restauración vegetal de los terrenos. Otro ejemplo, todavía sin ejecutar, es la sentencia del Tribunal Supremo de Justicia de Andalucía, que ordenó la demolición del polémico hotel "Algarrobico", ubicado en Carboneras (Almería) y cuyas obras están paralizadas desde el año 2006. El edificio permanece actualmente en pie y con un coste estimado de demolición de unos 7 millones de euros.

\section{Reactivación}

A día de hoy esta alternativa está siendo liderada por las entidades bancarias, actuales propietarios de urbanizaciones y edificios cuyos dueños iniciales no pudieron hacer frente al pago de hipotecas. También por promotores y grandes inmobiliarias, que han retomado la finalización de conjuntos residenciales paralizados desde hace años. Esta reactivación debería realizarse mediante procesos de gestión que faciliten el acceso de los sectores de la población más débiles, dando prioridad a estas áreas a medio desarrollar antes que plantear nuevos crecimientos urbanos. Aunque la situación periférica de estos lugares, combinada con la falta de vida y servicios, provoca que los bajos precios ofrecidos no sean un aliciente lo suficientemente atractivo para su adquisición.

\footnotetext{
${ }^{76}$ Ciudades Menguantes, El Blog de Fariña: http://elblogdefarina.blogspot.com.es/2015/02/ciudadesmenguantes.html [Fecha de consulta: 22 de julio de 2015]
} 


\section{Reutilización y reciclaje}

Otras actuaciones están dirigidas al aprovechamiento de recursos y energía ya consumida, de cara a la sostenibilidad global del planeta. La idea principal es reciclar y transformar edificios y espacios abandonados en lugares habitables, con nuevos usos. En este sentido existen experiencias que nos pueden servir de referencia, como el caso de la ciudad de Detroit, donde dos emprendedores pretenden aprovechar los terrenos abandonados para crear uno de los huertos urbanos más grandes del mundo. Otra iniciativa en la misma ciudad es la de una empresa que está realizando un "experimento agrícola" introduciendo ganado mediante la compra de varias propiedades para que pueda pastar entre los jardines y edificios abandonados. La gestión y parte de los beneficios repercutirán en personas desempleadas de la localidad 77 . Curiosamente este es el destino al que han sido abocados gran parte de los terrenos urbanizados vacíos de nuestro país.

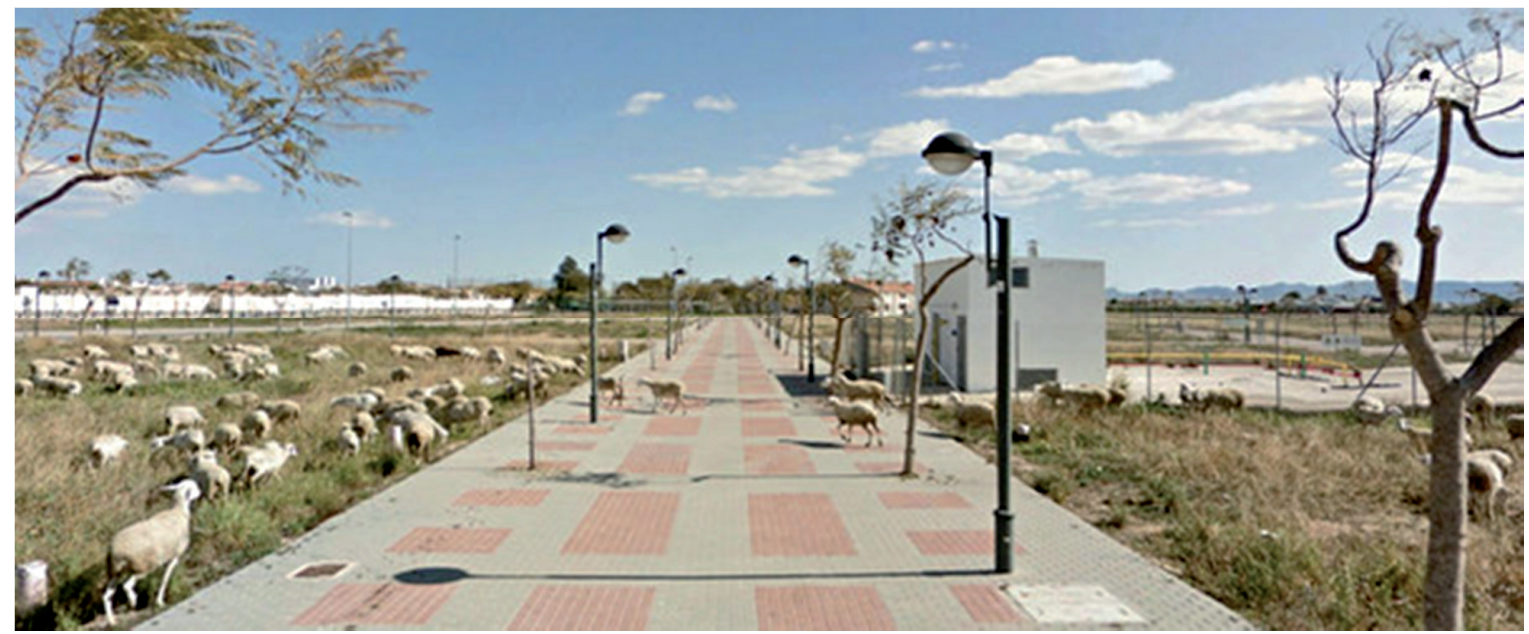

Figura 11. Ganado pastando en terrenos urbanizados vacíos en algún lugar de España Fuente: Nacion Rotonda, http://www.nacionrotonda.com

En España el colectivo Recetas Urbanas ${ }^{78}$ recurre al reciclaje y la reutilización de suelos y edificios vacíos para construir espacios y edificios autogestionados. Otras iniciativas interesantes son las realizadas por el proyecto Esto no es un solar, que se dedica a la recuperación, mantenimiento y reactivación de espacios urbanos abandonados dentro de las ciudades o la promovida por la Red Internacional de Colectivos: Arquitecturas Colectivas, que acaba de publicar una colección de guías para la activación de espacios de estas características: Activar un inmueble en desuso / Protocolo para la activación de vacíos urbanos autogestionados / Guía para la activación del espacio público. ${ }^{79}$

\footnotetext{
77 El Mundo: http://www.elmundo.es/economia/2014/06/09/53920114e2704e5e6f8b4575.html [Fecha de consulta: 10 de julio de 2015]

78 Recetas Urbanas: http://www.recetasurbanas.net

79 Arquitecturas Colectivas:

http://arquitecturascolectivas.net/herramientas/grupos/guias-para-la-activacion-de-espacios-de-aaccversion-para-imprimir
} 
En Madrid, estudiantes de postgrado de la ETSAM han desarrollado una propuesta denominada Splash\#Madrid para la reutilización de un edificio en fase de estructura que fue construido como Centro Acuático para el sueño del "Madrid Olímpico". Las obras se iniciaron en el año 2004 y se paralizaron en 2010, cuando el ayuntamiento ya había invertido 89 millones de euros. Los alumnos proponen un espacio de ocio para los vecinos del Barrio de San Blas, como cines de verano, festivales al aire libre, terrazas, etc., utilizando las parcelas aledañas para jardines y huertos urbanos ${ }^{80}$

La puesta en marcha de actuaciones imaginativas a pequeña escala en este tipo de espacios, podría ser el motor de acciones y sinergias de carácter mucho más amplio.

\section{Reflexiones para el debate}

Los procesos de declive, abandono y transformación de áreas urbanas no son nuevos. La historia de la humanidad ofrece numerosos ejemplos, como el abandono de castillos y ciudades debido a invasiones, epidemias, desastres naturales, etc. Restos urbanos contenidos que fueron procesados por el medio ambiente a lo largo de los años, e incluso incorporados de nuevo al ciclo constructivo mediante su reutilización en nuevos edificios y espacios urbanos. La gran diferencia con los procesos urbanizadores de la última década, es la voracidad y velocidad con la que estos se han producido, provocando que el soporte territorial y la sociedad que lo habita tengan grandes dificultades para asimilarlos, dejando un panorama desolador, con una extensión de notable presencia.

Estos desarrollos urbanísticos se ofrecieron a las comunidades locales como motores de generación de empleo, desarrollo y bienestar, pero se paralizaron bruscamente debido, entre otras causas, a su inviabilidad y a una crisis que dura ya varios años, tiempo que no ha servido para la reflexión sobre lo ocurrido, puesto que la gran mayoría de casos están en barbecho, esperando que vuelvan tiempos "mejores".

De cara al futuro, la formulación de actuaciones para la reactivación y/o recuperación de estos lugares debería tener en cuenta el nuevo panorama socioeconómico generado tras la crisis, así como las múltiples situaciones geográficas y culturales de cada uno de los territorios donde se han generado. Todo ello acompañado por una revisión crítica de los procesos e instrumentos legales, económicos, sociales, etc. que permitieron la creación de estos paisajes de la vergüenza.

${ }^{80}$ Departamento de Proyectos: http://dpa-etsam.com/tag/splashmadrid/ 